\title{
ПРОЕКТ ОЭСР ВЕРS: OVERVIEW, НЫНЕШНЕЕ ПОЛОЖЕНИЕ И ПЕРСПЕКТИВЫ РАЗВИТИЯ
}

\section{OECD BEPS PROJECT: OVERVIEW, CURRENT SITUATION AND PROSPECTS}

A. Sapezhinskaya

Summary. The Organization for Economic Co-operation and Development (OECD) has achieved significant results over more than ten years of its work in the field of countering base erosion and profit shifting (BEPS), as well as in the field of taxation of the digital economy. This article discusses the main stages in the development of the OECD BEPS plan, namely: the initial 15 Actions aimed specifically at de-offshorization of the economies of the participating countries, The Multilateral Convention to Implement Tax Treaty Related Measures to Prevent Base Erosion and Profit Shifting, as well as the BEPS2.0, which emerged from the development of Activity 1 and is already aimed at equitable distribution of taxes for countries in the field of e-commerce and the digital economy. If initially the OECD BEPS was more beneficial to developed countries with a high level of taxation and The United Nations Model Double Taxation Convention, which protected the source country, was a full-fledged opponent, then the BEPS2.0, which aims at equitable distribution of taxes in the digital economy, supports developing countries, thereby becoming unique in the field of international legal cooperation. If it is possible to achieve a consensus between the participating countries (of which there are already more than 130) on the BEPS2.0, then this could become the beginning of a new stage of international legal cooperation in the field of taxation and will affect almost all multinational corporations.

Keywords: jurisprudence, international law, tax law, deoffshorization, international organizations, $\mathrm{OECD}, \mathrm{BEPS}$, UN, digital economy, taxation.

B условиях экономической глобализации национальное законодательство в сфере налогообложения не всегда успевает развиваться и меняться в соответствии с новыми обстоятельствами, вызванными, например, усложнением деятельности ТНК, развитием цифровой экономики и т.п. Одной из стратегий, которую использует ТНК для снижения своего налогового бремени является BEPS. BEPS (base erosion and profit shifting), дословно переводится как размывание налоговой/налогооблагаемой базы и вывод доходов/ прибыли из-под налогообложения, и заключается в том, чтобы искусственно вывести свои доходы из страны с высокими налоговыми ставками, где данные доходы на самом деле генерируются, в страны с низкими/нуле-
Сапежинская Анна Антоновна

Аспирант, Дипломатическая академия

Министерства иностранных дел Российской

Федерачиu

Amy2006@yandex.ru

Аннотация. За более десяти лет своей работы в сфере противодействия размывания налоговой базы и вывода прибыли/доходов из-под налогообложения (BEPS), а также в (фере налогообложения цифровой экономики Организация экономического сотрудничества и развития (ОЭСР) добилась значительных результатов. В данной статье рассмотрены основные этапы развития проекта ВEPS ОЭСР, а именно: первоначальные 15 Мероприятий, направленных именно на деофшоризацию экономик стран-участниц, Многосторонняя конвенция по имплементации связанных с налоговыми соглашениями мерами для предотвращения BEPS, а также проект BEPS2.0, который появился из развития Мероприятия 1 и направлен уже на справедливое распределение налогов для стран в сфере электронной коммерции и цифровой экономики. Если изначально проект BEPS ОЭСР был выгоден скорее развитым странам с высоким уровнем налогообложения и Типовая конвенция $00 \mathrm{H}$ об избежание налогообложения, защищавшая страну-источник дохода, представляла собой полноправного оппонента, Tо проект BEPS2.0, который направлен на справедливое распределение налогов в сфере цифровой экономики, поддерживает и развивающиеся страны, тем самым став уникальным в сфере международно-правового сотрудничества. В случае если удастся добиться консенсуса между странами-участниц (которых уже более 130) по проекту BEPS2.0, то это м0жет стать началом нового этапа международно-правого сотрудничества В сфере налогообложения и затронет практически все транснациональные корпорации.

Ключевые слова: юриспруденция, международное право, налоговое право, деофшоризация, международные организации, ОЭСР, BEPS, 00Н, цифровая экономика, налогообложение.

выми налоговыми ставки, где экономическая деятельность на самом деле практически не ведется.

Согласно данными ОЭСР, минимальные потери от размывания налоговой базы и вывода прибыли составляют 4-10\% общемировых сборов налога на прибыль, т.е. примерно от 100 до 240 млрд.

Проект ОЭСР BEPS нацелен на обеспечение стран мира эффективным инструментом налогообложения прибыли по месту осуществления генерирующей их экономической деятельности и создания стоимости, повышения прозрачности и универсальности международной налоговой среды для бизнеса. В настоящий 
момент к данной инициативе присоединилось более 130 стран.

Сейчас под словом BEPS подразумевается целый ряд структур и мероприятий:это первоначальный проект BEPS состоящий из 15 мероприятий, Инклюзивная группа, которая ежегодно отчитывается G20 (большая двадцатка, клуб правительств и глав центральных банков государств с наиболее развитой и развивающейся экономикой), MLI BEPS (Многосторонняя конвенция по имплементации связанных с налоговыми соглашениями мерами для предотвращения BEPS), проект BEPS2.0. 2020 года, состоящий из Планов 1 и 2 (Pillar 1 и Pillar 2), согласование которых ожидается в ближайшее время. План (Pillar) 1 предусматривает новый порядок налогообложения, в соответствии с которым международные корпорации, консолидированная выручка которых превышает определенный порог (ориентировочно 750 миллионов евро), уплачивают налог на прибыль в тех странах, где у них есть существенная клиентская база, даже при отсутствии традиционного «физического» присутствия (например, в виде дочернего предприятия или филиала). План (Pillar) 2 предлагает ряд правил, согласно которым международные корпорации будут обязаны уплатить налог не меньше, чем по глобально установленной минимальной ставке.

Чтобы определить нынешнее положение и перспективы развития инициативы ОЭСР, обратимся к истории плана BEPS и основным 15 мероприятиям и рассмотрим их подробнее.

Мероприятие 1. Решение проблем в сфере налогообложения цифровой экономики. Представляет собой анализ следующих вопросов: «цифровое» присутствие в другой стране без уплаты налогов ввиду «физического» отсутствия; определение стоимости, которая создается в результате передач информации пользователям посредством продажи/ оказания цифровых продуктов и услуг; определение источника дохода в новых моделях ведения бизнеса; обеспечение эффективного взимания НДС и налога на торговую деятельность и оказание услуг при международной торговле цифровыми товарами и услугами.

Отдельная группа мероприятий (Мероприятия 2-5) проекта BEPS направлена на достижение согласованности на международном уровне в сфере корпоративного налогообложения.

Мероприятие 2. Нейтрализации последствий действия гибридных механизмов, включая двойное налогообложение, долгосрочную отсрочку налогообложения или двойной вычет.
Мероприятие 3. Усиление правил деятельности контролируемых иностранных компаний. Сейчас во многих странах мира распространена практика вывода прибылей компаний-резидентов на уровень дочерних компаний, зарегистрированных в низконалоговых юрисдикциях.

Мероприятие 4. Ограничение уровня минимизации налогообложения путем вычета выплат по процентам и других финансовых платежей. Рассматривается проблема вычета процентных расходов для целей налогообложения, которая может привести к ситуации двойного неналогообложения в том случае, если компания привлекает или предоставляет заемное финансирование.

Мероприятие 5. Более эффективное противодействие неблагоприятной налоговой практике с учетом прозрачности и содержательности. Существует продолжающаяся «гонка уступок», приводящей к снижению ставок налога на прибыль и выводу прибыли международной компаний в низконалоговые юрисдикции.

Следующая группа мероприятий (Мероприятия 6-10) направлена на восстановление последствий и преимуществ международных стандартов.

Мероприятие 6. Предотвращение злоупотребления договорами. Данное мероприятие направлено на ограничение злоупотреблений соглашений об избежании двойного налогообложения (СИДН). ОЭСР предложила разработать «положения типового договора» (в настоящий момент оно уже разработано).

Мероприятие 7. Предотвращение искусственного уклонения от статуса постоянного представительства. Предполагает уточнение определения данного термина в связи с тем, что во многих странах мира национальное законодательство позволяет использовать так называемые комиссионные соглашения и вводить исключения из статуса «постоянного представительства» на период подготовительных и дополнительных видов деятельности.

Мероприятие 8. Проведение в соответствие результатов по трансфертному ценообразованию и увеличению капитализации: нематериальные активы. Включает разработка правил трансфертного ценообразования, которые будут препятствовать выводу прибыли путем перемещения нематериальных активов внутри группы компаний.

Мероприятие 9. Приведение в соответствие результатов по трансфертному ценообразованию и увеличению капитализации: риски и капитал. Было за- 
планировано разработать правила трансфертного ценообразования, препятствующие выводу прибыли путем переноса рисков или распределения избыточного капитала между членами группы.

Мероприятие 10. Приведение в соответствие результатов по трансфертному ценообразованию и увеличению капитализации: другие операции с высокой долей риска. Включает разработку мер в отношении сделок с высоким уровнем риска, не затронутых в Мероприятиях 8 и 9.

Последний крупный блок мероприятий (Мероприятия 11-14) направлен на обеспечение прозрачности, усиление достоверности и прогнозируемости.

Мероприятие 11. Создание методик сбора и анализа данных по BEPS и мер по решению данных вопросов.

Мероприятие 12. Обязательство налогоплательщиков уведомлять о применении агрессивного налогового планирования в своих соглашениях. Также подразумевается «формирование и внедрение усовершенствованных моделей обмена информацией между налоговыми администрациями о международных налоговых схемах».

Мероприятие 13. Пересмотр документации о трансфертном ценообразовании. Было предложение разработать универсальные правила по трансфертному ценообразованию.

Мероприятие 14. Создание более эффективных механизмов урегулирования споров.

Заключительное мероприятие Плана BEPS выделено в отдельный блок.

Мероприятие 15. Разработка многостороннего инструмента. Анализ практики, позволяющий различным юрисдикциям на добровольной основе реализовать мероприятия в отношении BEPS и внести соответствующие изменения в их двусторонние СИДН.

Наибольшее развитие получили Мероприятия 1,5,6,13 и 14.

Далее обратимся к истории создания ОЭСР данного проекта, как возникла данная инициатива и развивалась.

В 1998 г. ОЭСР был подготовлен доклад «Недобросовестная налоговая конкуренция: формирующаяся глобальная проблема». Данная работа была сосредоточена на трех основных направлениях: выявление и устранение неблагоприятных элементов преференциальных торговых режимов в странах ОЭСР, работа с «налоговыми гаванями», вовлечение в работу других стран, не являющихся членами ОЭСР.

Первые попытки создания самого проекта появились в 2009 году как реакция на международный финансовый кризис, а также как поиск решения для устранения недостатков в так называемой «международной налоговой системе» с целью повышения прозрачности, сокращения оффшорных зон и окончания эпохи «банковской тайны».

В 2010 году к проекту присоединилась G20. Лидеры «группы двадцати» обратились с призывом усилить работу по противодействию размытия налоговой базы в развивающихся странах. К февралю 2013 г. был опубликован доклад, в котором отмечалось, что часть существующих налоговых правил была разработана десятилетия назад. В результате чего, в современной ситуации, когда деятельность компании в какой-либо стране не обязательно требует физического присутствия, ценные активы (интеллектуальная собственность) крайне мобильны, а циклы производства товаров и услуг очень сложны с точки зрения определения налоговой базы, применение таких правил становится затруднительным либо невозможным.

В итоге, окончательный проект, возглавляемый комитетом ОЭСР по фискальным вопросам, был согласован G20 в сентябре 2013 года. Далее инициативная группа перешла к подготовке 15 мероприятий, о которых уже было сказано выше. Пакет данных мероприятий был представлен и единогласно одобрен членами ОЭСР и стран G20 в Анталии 15-16 ноября 2015 г. На этом же саммите было принято решение о создании и разработки инклюзивной группы. Инклюзивность в данном случае означала, что она открыта для заинтересованных стран и юрисдикций и позволяет им работать с ОЭСР по разработке стандартов по вопросам, связанным с BEPS, а также по анализу и мониторингу их внедрения.

Первая встреча Инклюзивной группы прошла с 30 июня по 1 июля 2016 г. в Киото, Япония, а вторая с 26 по 27 января 2017 г. в Париже, Франция.

Помимо Инклюзивной группы развитие проекта BEPS шло также по направлению сотрудничества с международными организациями и региональными фискальными организациями, в частности, с Африканским форумом налоговых администраций (ATAF), Межамериканским центром налоговых администраций (CIAT), Центром встреч налоговых администраций франкофонов (CREDAF) и т.д. 
Кроме того, разработка проектов 1 и 2 и модернизация 15 Мероприятий проходила в рабочих группах. Рабочие группы, будучи вспомогательными органами, проводят регулярные встречи и обсуждают проекты документов, подготовленных Секретариатом ОЭСР. В ноябре 2016 рабочей группой была доработана Многосторонняя конвенция по имплементации связанных с налоговыми соглашениями мерами для предотвращения BEPS. Первая церемония подписана ее прошла 5 июня 2017 г.

Российская Федерация подписала Многостороннюю конвенцию по имплементации связанных с налоговыми соглашениями мерами для предотвращения BEPS7 июня 2017 г., однако ратифицировала ее только 22 апреля 2019 г., приняв решение распространить действие документа на 71 соглашение об избежании налогообложения из 82 действующих. Тем самым Российская Федерация выбрала наиболее полным вариант реализации Конвенции.

В целом, планы BEPS продолжают развиваться постоянно. Сейчас создан так называемый проект BEPS2.0 состоящий из двух планов, о которых уже было сказано ранее. Мировое сообщество надеется прийти к общему соглашению к середине 2021 года.

Что же такое План 1 и 2? В чем они заключаются? Сам проект BEPS2.0 возник из модернизации Мероприятия 1. Решение проблем в сфере налогообложения цифровой экономики. 12 октября 2020 г. Организация экономического сотрудничества опубликовала планы предполагаемых действий для решения налоговых проблем, возникающих в результате ускоряющейся цифровизации и глобализации мирового экономики. Особое внимание в данных планах уделяется взаимосвязи и распределению прибыли, в дополнение к первоначальному «размыванию налоговой базы и выводу прибыли из-под налогообложения».

С помощью BEPS2.0 ОЭСР стремится решить фундаментальные проблемы мирового налогообложения. Например, План 1 соответствует концепции чистого налогообложения дохода, избежание двойного налогообложения и одновременного должен быть максимально понятным и изменяемым. Говоря простым языком, ОЭСР считает, что ТНК не платят достаточно налогов в тех юрисдикциях, где они на самом деле ведут рыночную деятельность.

Возьмем для примера Facebook (крупнейшая социальная сеть в мире и одноимённая компания Facebook, Inc., владеющая ею). Хотя у Facebook есть пользователи в каждой стране, сами операции, как и физическое присутствие во всех странах отсутствуют. В такой стране, как Египет, в Facebook зарегистрированы миллио- ны пользователей, рекламодатели нацелены на этих пользователей, а значит покупают рекламу и таргет y Facebook Inc. и компания получает доход и прибыль от этих рекламодателей. Однако, поскольку физическое присутствие в Facebook Inc. в Египте нет, компания не платит там налоги.

ОЭСР утверждает, что транзакции Facebook Inc. в Египте создают значительную ценность, поэтому компания должна уплатить некоторую сумму налога там. План 1 предоставляет Египту налоговые поступления от доли прибыли Facebook Inc., полученной в его юрисдикции.

Хотя он в первую очередь ориентирован на цифровые компании, План 1 также потенциально может применяться к предприятиям, ориентированным на потребителей, в которых компания, не имеющая физического присутствия в юрисдикции, продает продукты напрямую физическим лицам. В данную группу компаний входит, например, Amazon (американская компания, крупнейшая в мире на рынках платформ электронной коммерции и публично-облачных вычислений по выручке и рыночной капитализации) и т.п.

Перейдем к рассмотрению Плана 2 BEPS2.0. Согласно предложенной структуре, План 2 допускает «право на возраст уплаченного налога», т.е. он направлен на установку минимального уровня налогообложения ТНК. ОЭСР планирует установить пороговые значения эффективных налоговых ставок, и, если окажется, что в целом сумма налога, уплаченного ТНК, ниже данной ставки, ТНК будет необходимо доплатить налог.

План 2 будет применяться после Плана 1, а не одновременно. Компании сначала распределяют налог в зависимости от юрисдикции, в которой они получают доход в соответствии с принципами Плана 1 ОЭСР, а затем, если общий уплаченный налог все еще остается ниже порогового значения, то будут применяться руководящие принципы Плана 2.

В целом, проект BEPS2.0 еще не до конца утвержден и существуют спорные детали. Например, в каких компаниях данные планы будут применимы. Пока ОЭСР предполагает, что План 1 и План 2 будут применяться только к высокодоходным компаниям, годовой доход которых составляет не менее 750 миллионов евро.

Другие важные параметры, которые еще предстоит определить, это что представляет собой бизнес, ориентированный на потребителя, какие минимальные налоговые ставки и сумма прибыли, которая должна быть распределена между рыночными юрисдикциями, где компания не имеет физического присутствия. 
В настоящим момент ОЭСР обозначила 14 декабря 2021 г. крайним сроком для получения комментариев от стран-членов по предложениям, изложенным в BEPS2.0, после чего в январе 2022 года состоится открытое собрание. Организация надеется достичь подписания соглашения по окончательному проекту BEPS2.0 в середине 2022 г.

Однако, даже если ОЭСР все же придет к соглашению в 2022 году, руководящие принципы Плана 1 и Плана 2 не станут автоматически законом, принятие или отклонение каждого принципа по-прежнему остается прерогативой каждой отдельной страны, подписавшей соглашение. Но ТНК будет необходимо начать рассматривать потенциальные последствия от BEPS2.0 в любом случае, так как такое соглашение представляет собой полную перестройку текущих норм, регулирующих глобальные стратегии налогообложения и трансфертного ценообразования.

Каковы же последствия BEPS2.0 для мирового сообщества? Учитывая, как уже было сказано выше, что BEPS2.0 представляет собой огромное количество нововведений для действующего законодательства, то последствия для стратегий налогообложения и трансфертного ценообразования будут огромны. Используя проведенный выше пример Facebook, можно сразу задать множество вопросов: в случае принятие Плана 1 в нынешнем варианте, каков будет механизм распределения доходов в Египте, когда там по факту не существует внутрифирменных транзакций? Какая страна будет является контрагентом, у которой вычтут данные доходы? Как Facebook сможет заплатить налог в Египте, не имея там индивидуального номера налогоплательщика или его аналога?

Что касается Плана 2, то даже несмотря на то, что минимальный налоговый порог в нем не предусмотрен, компаниям следует сосредоточиться на юрисдикциях, где у них очень низкие эффективные налоговые ставки, чтобы оценить, куда им возможно придётся доплатить налог.

В целом, хотя предстоит еще огромная работа по определению всех деталей и тонкостей BEPS2.0, он представляет собой радикальный отход от текущей мировой налоговой политики. ТНК, которые будут затронуты, должны начать задумываться сейчас, как они будут реагировать, если и когда ОЭСР придет к соглашению и примет предложения, изложенные в проекте. Однако, несомненным остается то, что в отличие от своего первоначального Проекта, данные нововведения представляю собой быструю реакцию на изменение мирового порядка, а также попытки учесть интерес не только развитых стран, но и развивающихся.
Существует ли альтернативные площадки для стран для сотрудничества в сфере налогообложения? Да, но являются ли они настолько же эффективными? Хотелось бы обратиться здесь к практике ООН. Помимо ОЭСР и G20 о необходимости сотрудничества стран в сфере налогообложения заговорила и ООН. Хотя ОЭСР имеет главенствующую роль в данной сфере, так как помимо большого количества участников (139), организация также разработала 15 Мероприятий и 2 проекта действий, которые успешно внедряются в политику стран-участниц, ООН уже включила новую статью 12В по налогу у источника выплаты на цифровые услуги в «Типовую конвенцию ООН по избежанию двойного налогообложения». Но в отличие от статьи 12В, Многосторонняя конвенция по имплементации связанных с налоговыми соглашениями мерами для предотвращения BEPS, вытекающая из 15 Мероприятий, предлагает модель более скоординированного и эффективного подхода к внесению изменений в налоговые соглашения.

Однако, у ООН есть особенности инициатив, отличные от ОЭСР, которые можно было бы применить и ОЭСР, например, группа ООН по международной финансовой отчетности, прозрачности и честности опубликовала в феврале 2021 года (т.е. совсем недавно, в то время как ОЭСР начала работать в этом направлении еще в 2015 году) свой отчет, содержащий 14 основных рекомендаций. В соответствии с, например, Рекомендацией 2 комиссия отметила следующее: «Чтобы ускорить внедрение статьи 12В, Типовая конвенция ООН должна содержать положения, согласно которым ее условия будут автоматически включены в налоговые соглашения подписавших сторон, чтобы им не приходилось пересматривать отдельные двусторонние соглашения». Данная рекомендация является очень важной, так как, например, у Российской Федерации в настоящий момент свыше 80 действующих соглашений об избежании двойного налогообложения и изменять каждое из них является трудоемким. Кроме того, в соответствии с Рекомендацией 4А комиссия среди прочего отметила, что «справедливое налогообложение цифровой экономической деятельности требует равного отношения к цифровому бизнесу и бизнес-моделям с традиционным бизнесом».

Можно отметить существенные различия в рекомендациях ООН по статье 12В и ОЭСР по планам 1 и 2 (консенсус между ними еще не достигнут). Однако, статья 12В Модельной конвенции ООН в целом соответствует Плану 1 ОЭСР. Сравнительная позиция рекомендаций ООН и ОЭСР выглядит следующим образом (таблицы 1, 2).

Три основных составляющих работы ОЭСР и ООН это: мандат, состав целевой группы и поддержка секретариатов. 
Таблица 1

\begin{tabular}{|l|l|l|}
\hline Наименование & Рекомендации ООН & Рекомендации ОЭСР \\
\hline Охват рекомендаций & Узкий (только статья 12В) & Широкий (План 1 и План 2) \\
\hline $\begin{array}{l}\text { Рекомендация фиксированной } \\
\text { доходности для определенных базовых } \\
\begin{array}{l}\text { маркетинговых и дистрибьюторских } \\
\text { мероприятий }\end{array}\end{array}$ & Нет & Да (План 2) \\
\hline $\begin{array}{l}\text { Рекомендация платить минимальный } \\
\text { уровень налогообложения }\end{array}$ & Да & Да (План 2) \\
\hline
\end{tabular}

Таблица 2

\begin{tabular}{|l|l|l|}
\hline Наименование & Статья 12В & ОЭСР План 1 \\
\hline Поле деятельности & $\begin{array}{l}\text { Узкое: охватывает только } \\
\text { автоматизированные цифровые сервисы }\end{array}$ & $\begin{array}{l}\text { Широкое: охватывает автоматизированные } \\
\text { цифровые услуги и бизнес, } \\
\text { ориентированный на потребителя }\end{array}$ \\
\hline Порог реализации & Не существует & Существует \\
\hline Распределение прибыли & На валовую и чистую прибыль & На чистую прибыль \\
\hline Положение о разрешение спора & Нет & Да \\
\hline Реализация & Легко реализуемо & Сложно реализуемо \\
\hline
\end{tabular}

Что касается мандата, то инклюзивная группа ОЭСР (G 20) была уполномочена подготовить отчеты по проектам BEPS1 и BEPS2.0, что подразумевает, что Группа 20 специально уполномочила ОЭСР выполнять эту задачу, в то время как аналогичный институциональный мандат международного масштаба лежит на ООН. Комитет экспертов по международному сотрудничеству в налоговых вопросах (Налоговый комитет ООН) работал над налогообложением цифровой экономики в рамках своего обычного курса работы с 2017 по 2021 год. И только сейчас комиссия в своем отчете от февраля 2021 года предусматривает, что налогообложения автоматизированных цифровых услуг должно быть отмечено в Типовой конвенции ООН.

Поддержка от секретариата организации также играют очень важную роль. Секретариат ОЭСР состоит из 3300 сотрудников, включая экономистов, юристов, ученых, политических аналитиков, социологов, экспертов, статистов и т.д., которые оказывают огромную поддержку развитию Планов 1 и 2 и в целом Многосторонней конвенции по имплементации связанных с налоговыми соглашениями мерами для предотвращения BEPS. секретариат ООН же является абсолютно обособленным от Налогового комитета и выполняет множество функций, так что не может является такой же опорой для Налогового комитета $\mathrm{OOH}$, как секретариат ОЭСР для инклюзивной группы.

Почему же G20 в первую очередь уполномочила ОЭСР работать над мерами против размывания налоговой/налогооблагаемой базы и вывод доходов/при- были из-под налогообложения, а не возложила эту ответственность на ООН или любую другую международную организацию, такую как МВФ или Всемирный банк. Полагается, что одним из важных факторов, повлиявших на это решение, является сильная техническая поддержка, оказываемся инклюзивной группе секретариатом ОЭСР. Ведь очевидно, что техническая поддержка Налогового комитета ООН не соответствует уровню ОЭСР. Статья 12В в Типовой конвенции ООН рассматривается как работа 25 членов комитета, хотя и служащих налогового отдела, но работающих в своем личном качестве. В отличие от этого, рекомендации ОЭСР по Плану 1 и Плану 2 рассматриваются как участие в инклюзивной группе 139 государственных чиновников.

Если ООН в ближайшее время не выйдет из тени ОЭСР по данному вопросу, то его рекомендации по новым положениям в Типовой конвенции ООН, не будут включаться в новые двухсторонние соглашения, так как они будут противоречить рекомендациям ОЭСР.

Хотя развитие Типовой конвенции ООН находится в интересах развивающихся стран, а ОЭСР в своей работе в основном опиралась на интересы и опыт развитых стран, в настоящий момент проект BEPS2.0. также предполагает поддержку развивающихся стран, поэтому, пока можно сделать вывод о том, что глобальной альтернативной плану BEPS ОЭСР в мире нет.

В целом, проект ОЭСР BEPS, BEPS2.0. и Многосторонняя конвенция представляют собой эксклюзивною пло- 
щадку для международно-правового сотрудничества В сфере налогообложения. В настоящий момент, например, полноценно начал работать международный обмен налоговыми данными между участниками. Если сравнить мировой рынок 10 лет назад и сейчас, тенденция к окончанию эпохи «банковской тайны» и офф- шорных зон набирает обороты. Конечно, пока BEPS2.0 кажется больше утопией, чем реальностью, однако, это большой шаг в развитие договорной базы для цифровой экономики, которая становится все более распространённой, и с которой страны пока еще не до конца знают, как работать.

\section{ЛИТЕРАТУРА}

1. Налоговый обзор от экспертов PWC. — Октябрь 2020 г.— - Выпуск № 54. «Простыми словами о BEPS2.0»

2. Gabriel Zucman; Thomas Wright, «THE EXORBITANT TAX PRIVILEGE". National Bureau of Economic Research: - 11— (September 2018).

3. Dhammika Dharmapala, "What Do We Know About Base Erosion and Profit Shifting? A Review of the Empirical Literature".— University of Chicago. — 2014 — p. 1

4. Mihir A. Desai, "Tax Reform: Round One".- - Harvard Magazine. - June 2018

5. Google, Facebook and Salesforce.com dramatically expand their Dublin office hubs"._— Irish Independent. — 26 July 2018.

6. Covington \& Burling LLP, International Tax Update: U.S. Outlines Position on OECD BEPS2.0 Project [электронный pecypc] — https://www.lexology.com/ library/detail.aspx?g=a0841fd7-2072-4ce7-8ea4-69643bb4929f

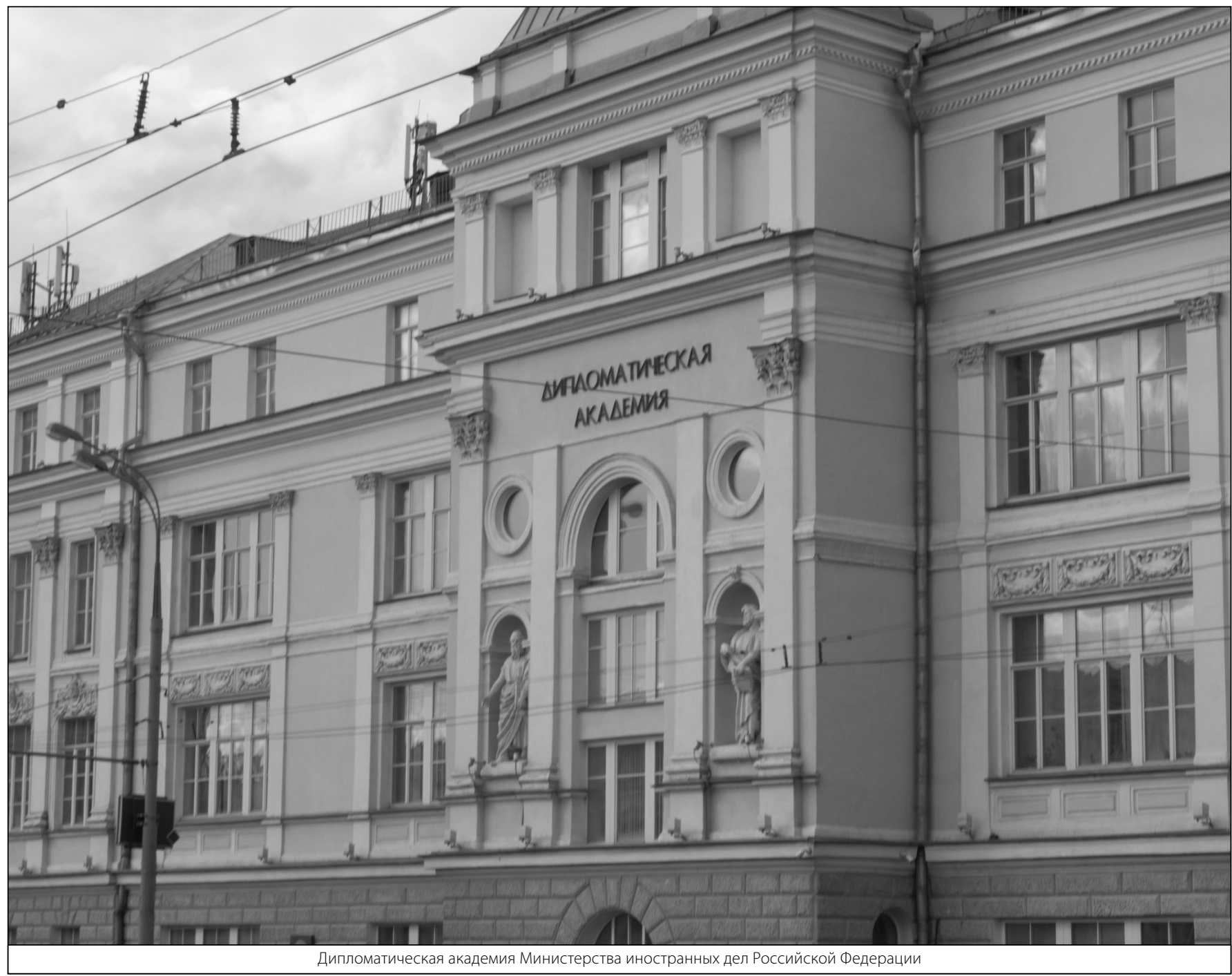

